\title{
Spectroscopy Characterization of Ethylene Vinyl Acetate Degradation by Different Kinds of Accelerated Aging
}

\author{
Mohammed A. Akraa
}

Ali S. Hasan

Mohammed Jawad H. Kadhim

Department of Engineer of Polymers and Petrochemical Industries, College of Material's Engineering, University of Babylon, Babylon, Iraq.

*Corresponding author: $\quad{ }^{*}$ mat.mohammed.akraa@uobabylon.edu.iq, $\quad$ mat.ali.salah@uobabylon.edu.iq, mat.mohammed.jawad@uobabylon.edu.iq

*ORCID ID: "https://orcid.org/0000-0002-5176-142X, https://orcid.org/0000-0002-5038-6525, https://orcid.org/0000$\underline{0002-2278-0007}$

Received 15/9/2019, Accepted 8/1/2020, Published 1/9/2020

This work is licensed under a Creative Commons Attribution 4.0 International License.

\begin{abstract}
:
This paper presents a sight about the chemical structure deformation of poly (ethylene-co-vinyl acetate) (EVA) samples according to the change ratio of rate constant values. Spectroscopy kinetics fluorescence curves are fitted for two characteristic wavelength domains of fluorescent intensities. The short wavelengths $(320-400 \mathrm{~nm})$ domain show spectra overlapping, while at long wavelengths $(400-800 \mathrm{~nm})$ domain spectra are arranged in regular for each specific accelerated aging time. The ratio of kinetics rate constant at long wavelengths to kinetics rate constant of short wavelengths is the criterion of the degree chemical structure deformation. Molar extrinsic coefficient relies on the chemical structure change. Through absorbance measurement, EVA samples have been classified into two groups. Presence of Cyasorb additive is the key point of the ranking. The effect of three different accelerated aging of dry $\left(115{ }^{\circ} \mathrm{C}\right)$, damp $(85 \%$ moisture, $85^{\circ} \mathrm{C}$ ), and irradiated $\left(\mathrm{UV}, 65^{\circ} \mathrm{C}\right)$ aging have been considered for two samples of each group over different aging time. Spectroscopy of absorbance and fluorescent for aged samples have been discussed. In general, Cyasorb adding causes higher chemical structure deformation for the EVA sample. The most effective factor is the damp aging and the less one is the UV irradiation aging, while the biggest chemical structure change of Cyasorb-free sample is produced by damp aging and the less by dry heat.
\end{abstract}

Key words: Accelerated aging, Aging characterization, Ethylene Vinyl Acetate, Polymer thermal degradation, Solid state luminescence.

\section{Introduction:}

Earlier, although ethylene-vinyl acetate EVA did not have the best combination properties, yet it was chosen for economic reasons (that is, its being inexpensive). EVA has excellent adhesion, good electrical insulation, good mechanical properties to protect modules from mechanical damage and environmental corrosion which is caused by accumulation of water at the interface. EVA has a good optical transmittance and high transparency $(1,2)$. These properties are not constant, but affected by the structure of EVA and the environmental effects. Moreover, EVA is a copolymer which consists of about $67 \mathrm{wt} \%$ polyethylene and $33 \mathrm{wt} \%$ polyvinyl acetate (3). Unless these two components are compiled with each other in one copolymer, they will, separately, have unsuitable properties as encapsulation material. As regards polyethylene, despite its simplicity and cheapness, it is often an opaque or translucent (depending on the polymerization conditions) semi crystalline polymer of a modulus being of enough mechanical properties to protect a photo voltaic PV device. On the other hand, poly vinyl acetate is a transparent and an amorphous polymer. But it has a glass transition temperature $\mathrm{Tg}$ of about $35^{\circ} \mathrm{C}$, keeps it too brittle under typical environment exposure. It is so helpful to break up the crystallites of the polyethylene by adding a rate of about $33 \mathrm{wt} \%$ of poly vinyl acetate to produce a copolymer of EVA of high optical transmission and a low $\mathrm{Tg}$ (3). Severe failures began to occur because of EVA yellowing which appeared within a few years of the usage $(1,4,5)$. That led to produce newer EVA formulations of better antioxidants and ultraviolet UV absorbers for the same base resin, to overcome this problem of yellowing over a 20-30 year lifetime of a module (6). This phenomenon has been discussed by selecting module manufacturers, SERI 
staff, and a representative from Spring Born Laboratories, Inc. (5). Many factors have been found to produce this discoloration which is described by different terms as yellowing, browning, brown cell, amber, and degradation. These factors include elevated temperature, UV light, the combination of high temperature and UV light, and effects of module construction. At elevated temperature, EVA thermolysis by acetylation is well known to produce acetic acid as a main decomposition and unsaturated groups in the backbone of the polymer (7). The rate is reported, the increasing vinyl acetate content in the EVA leads to more EVA thermal degradation (8). It is found (9), that the optimization and characterization of the EVA are possible by the utilization of the degradation-induced the photoluminescence of the copolymer.

This paper aims to evaluate the performance of six labelled samples of EVA (070, $426,444,445,643$, and 644) by using nondestructive methods. The transparence samples of chemical formula $(\mathrm{C} 2 \mathrm{H} 4) \mathrm{n}(\mathrm{C} 4 \mathrm{H} 6 \mathrm{O} 2) \mathrm{m}$ contain additives of unknown chemical composition. The assessment has been achieved by using characterization involves spectroscopic fitted kinetics of both UV-visible absorbance for wavelengths 200-800 nm and fluorescence spectroscopy of filtered excitation wavelength 280 $\mathrm{nm}$. Throughout accelerated aging time over different durations (more than three thousand hours) for specimens of different groups denoted by marks $\left(+,{ }^{*}, 0\right)$. Samples are exposed to diverse conditions comprise dry heat at $115^{\circ} \mathrm{C}$, UV irradiation at $65^{\circ} \mathrm{C}$ aging, and damps aging (moisture of $85 \%$ and 85 $\left.{ }^{\circ} \mathrm{C}\right)$.

\section{Materials and Methods:}

Materials: The investigated samples of EVA copolymer are six types of different labels, according to the Table 1 below:

Table 1. Each sample versus its label by the supplier company.

\begin{tabular}{lc}
\hline Sample & Label \\
\hline S1 & 070 \\
S2 & 426 \\
S3 & 444 \\
S4 & 445 \\
S5 & 643 \\
S6 & 644 \\
\hline
\end{tabular}

The samples of EVA foils are stuck on polymeric frames windows in their middle to facilitate their handling. Three varieties of accelerated aging for the samples consistent with the natural environmental effects have been accomplished by special ovens. Dry aging involves circulating aeration of dry heating at a temperature of $115{ }^{\circ} \mathrm{C}$, damp heating at $85^{\circ} \mathrm{C}$ accompanied by the moisture of percentage $85 \%$, and UV aging at $65{ }^{\circ} \mathrm{C}$ for different intervals. All the measurements are accomplished for the cured EVA samples, by higher cross linking, because this state of the copolymer is applied in the photovoltaic module structure. However, they have been differentiated from those of uncured samples for more identifications. The latter samples have non-smooth surface which differs from those of cured samples.

\section{Methods of work: \\ Fluorescence measurement}

The fluorescence measurements were performed by using Jasco FP-8500 fluorescence spectrometer supplied with filters to adjust the excitation and emission wavelengths, moreover, to avoid the stray light which comes with the excitation light. It is very weak because of the high efficiency of the monochromatic. When this influence is compared to the fluorescence intensity; light should be removed. The used holder of samples is designed in somehow to detect the fluorescence with an angle of deflection $30^{\circ}$ from the incident light direction. This posture helps to ensure no reflected light receiving with the detected signal. The utilized excitation wavelength of the $2 \mathrm{D}$ spectroscopy test equals $280 \mathrm{~nm}$ and the domain of the detected emitted signal is between $320-800$ nm.

\section{Absorbance measurements}

The absorbance test for the EVA samples is achieved by using the instrument of SHEMADZU UV-VIS Spectrophotometer, UV-2450. The detected light is up to $750 \mathrm{~nm}$.

\section{Results and Discussion:}

Absorbance measurement for non-aged samples

Before the aging process of the samples, it is useful to identify their absorbance. Figure 1, shows the absorbance of two groups of six specimens, (a) cured and (b) uncured EVA copolymer. Obviously, the spectra of the cured samples Fig. 1a are shifted downward in comparison with below spectra of uncured EVA Fig.1b by about one absorbance unit. The spectra of cured EVA, beyond about $400 \mathrm{~nm}$ coincide on the $\mathrm{X}$-axis. But that is not correct for uncured EVA, this change can be attributed to the radiation scattering from rough uncured EVA surface (for industrial necessity). The two bands show absorbance at 290 and $340 \mathrm{~nm}$ which matches the absorbance of the UV absorber type of Cyasorb. The absorbance 
refers to the existence of carbonyl group double bonds in addition to two aromatic rings (10). The noteworthy thing is not all the samples have this type of UV absorber, where absorbance spectra of S4 and S6 do not show the characteristic spectrum of this additive type.

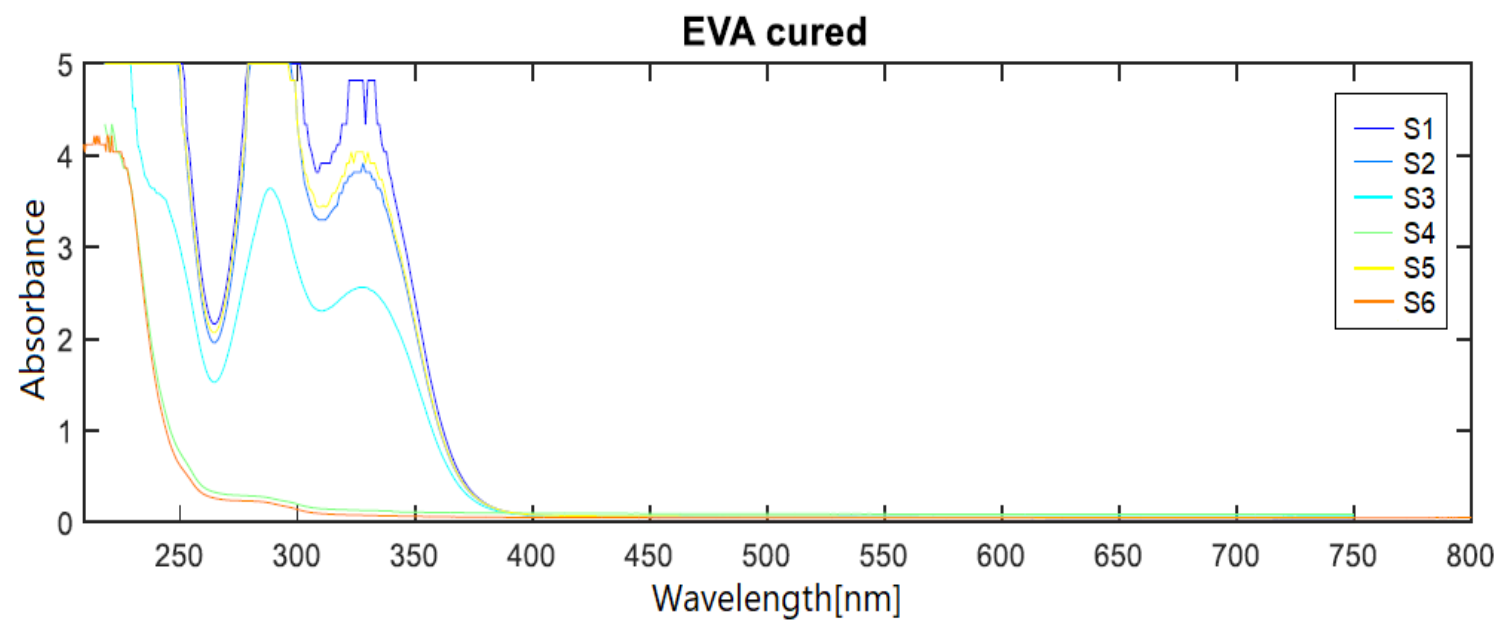

(a)

EVA uncured

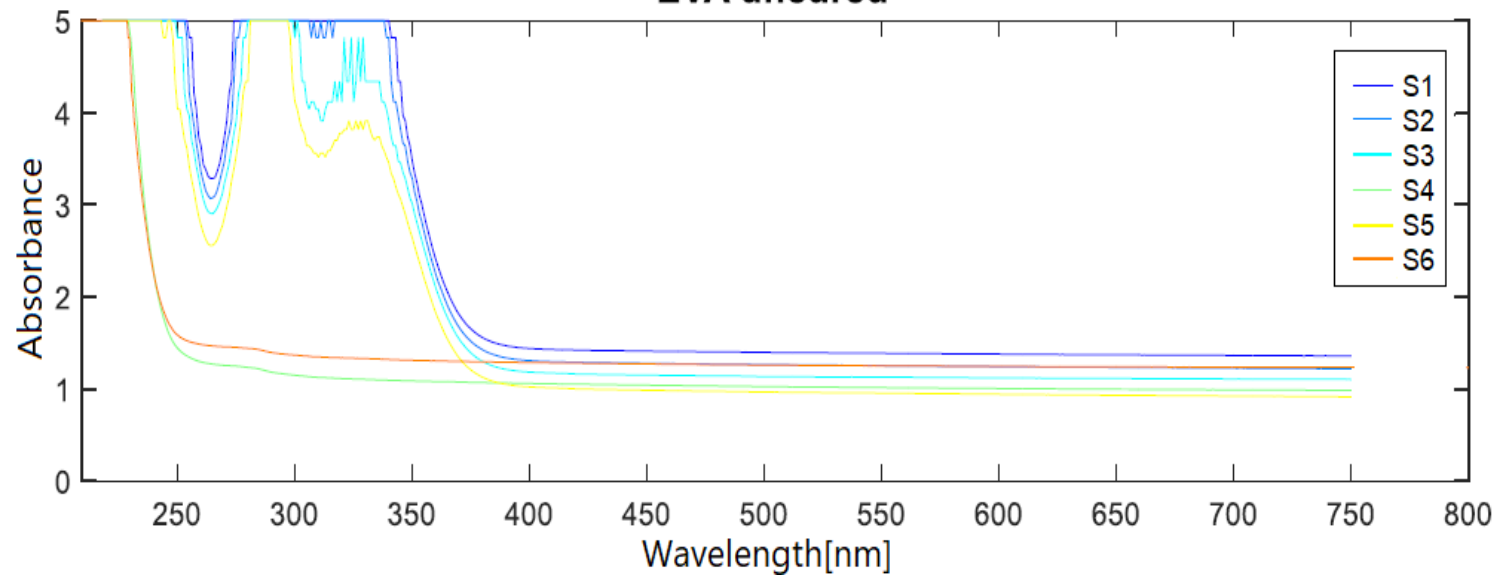

(b)

Figure 1.The clarity of difference between the absorbance spectra of unaged EVA sample of (a) cured, and (b) uncured.

Then there are two classes of samples, the first one contains UV absorber with different concentrations and the second one without the UV absorber. According to the spectra, Fig.1, as S1 has the highest concentration, then S5, S2, and S3. Since,

$\mathrm{A}=\varepsilon . \mathrm{c.} 1$

A is the absorbance, $\varepsilon$ is the molar extinction (mol/L.cm), $\mathrm{c}$ is the concentration (particles. mol ${ }^{-1} \cdot \mathrm{L}^{-1}$ ), 1 is the length of the light path through the sample in $\mathrm{cm}$.

The ratio of ca. 30\% PVA gives the best stability for the copolymer EVA within the requested specifications. PVA as a component of EVA suffers degradation by deacetylation and leads to produce acetic acid as a volatile material $(11,12)$.
Fluorescence measurement for non-aged samples

Cyasorb effect upon fluorescence production is very clear for the two groups of uncured and cured EVA, Fig.2, up to ca.400 nm. The emitted intensity of fluorescence of the first EVA class (with UV absorber) is very low compared to the second class (Cyasorb-free EVA).

The highest fluorescence can be seen at 325 $\mathrm{nm}$ for all the spectra of EVA samples, due to using filters for the emission wavelengths start at $325 \mathrm{~nm}$. This fluorescence continues to even longer than $400 \mathrm{~nm}$. For cured samples, fluorescence intensity of $\mathrm{S} 4$ is higher than S6. This may refer to the curing degree of S4 higher than that of S6, Fig.2b. 


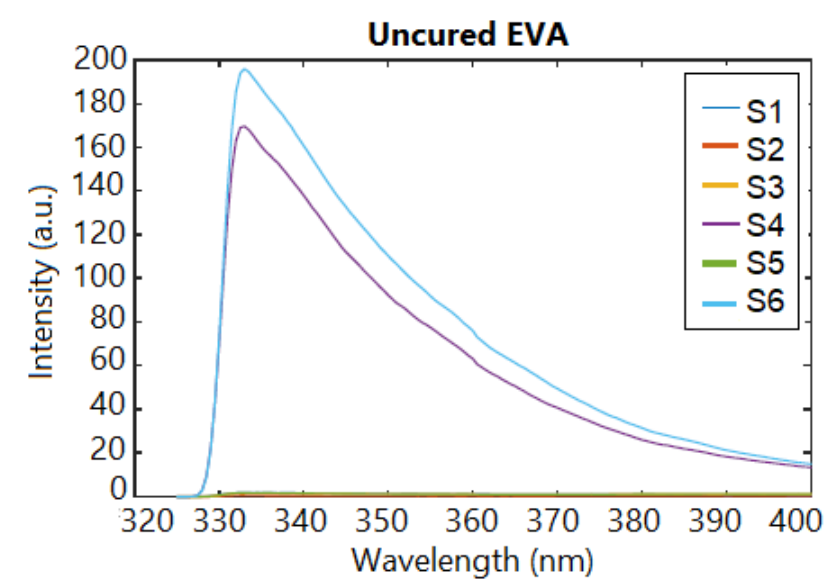

(a)

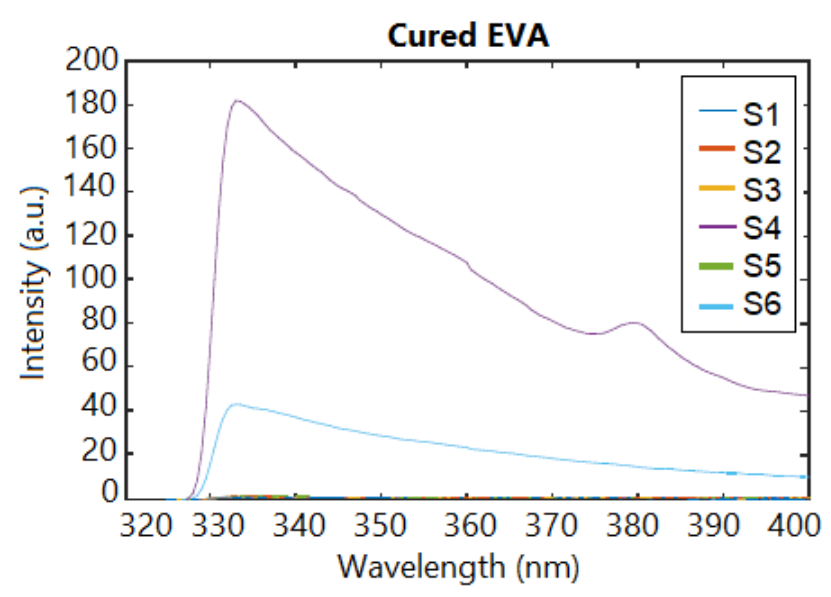

(b)

Figure 2. the obvious role of Cyasorb absent in increasing the fluorescence spectra from unaged EVA samples fluorescence (a) uncured, (b) cured copolymer.

\section{Absorbance measurement of aged samples}

The two deduced classes are represented by samples S3 and S4. Absorbance spectroscopy of the aged cured samples S3 and S4 show a clear difference between the two EVA classes, as shown below in Fig. 3 and 4 respectively.

All the labelled samples are exposed to different conditions of aging; dry heat at $115^{\circ} \mathrm{C}$, damp aging at $85 \%$ moisture and $85{ }^{\circ} \mathrm{C}$, and UV irradiation at $65{ }^{\circ} \mathrm{C}$ heats for different aging times respectively. Sample S3 which represents the first class (contains Cyasorb) has characteristic spectra of UV absorber, see Fig.1a. In case of dry heat Fig.3, spectrum intensity beyond $25 \mathrm{~h}$ decreases with aging time, which refers to degradation occurrence for UV absorbers. For the other two conditions, Cyasorb has better stability, especially for damp aging. Absorbance spectrum shows intensity lower than that of damp aging due to UV aging condition.
Figure 4 shows absorbance of sample S4, where it is at the lowest value in the case of UV aging and at the highest value in state damp aging. The absorbance band possibly denotes to carbonyl group absorption as well as some extension in base of damp aging band. It might indicate overlapping with another band.

This becomes very clear when a comparison is made with an absorbance band of dry aging case, while a band of the latter aging is steeper than that of damp aging.

In case of UV aging, temperature is not effective, especially at $65{ }^{\circ} \mathrm{C}$ (13). The affected temperature starts after $85{ }^{\circ} \mathrm{C}(7)$. In general, all the aging time conditions cause continual absorption evolution in varying levels of the same pattern; except for dry aging which produces a pattern change of absorbance spectra especially for sample S3 over different aging durations. This characteristic degradation of Cyasorb additives is increased by heat.
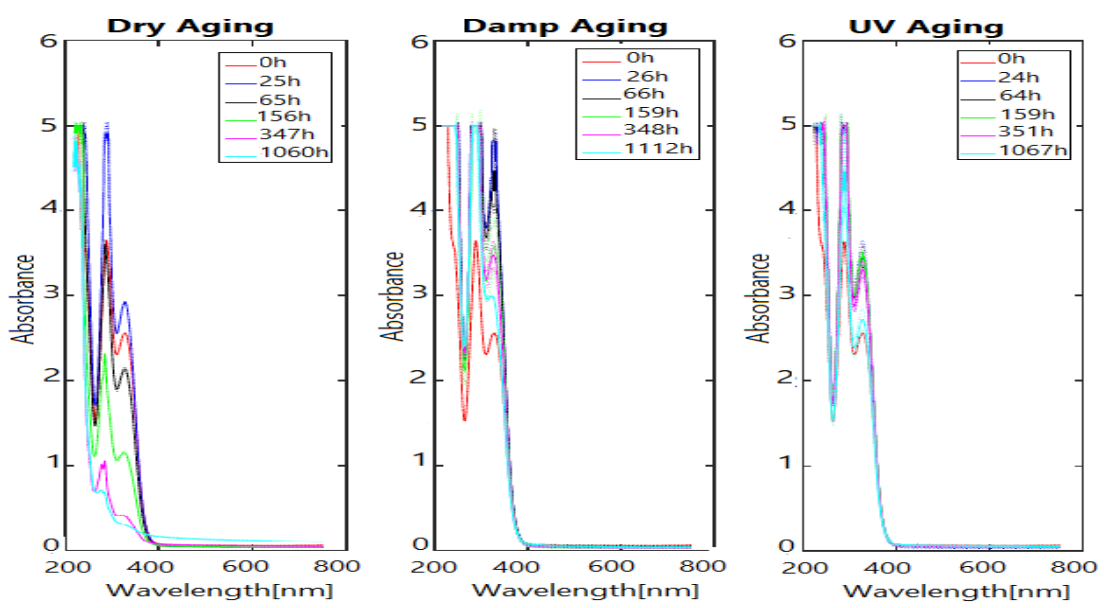

Figure 3. absorbance spectra variation of sample S3 in accordance to the different aging conditions of dry, damp, and UV heat. 

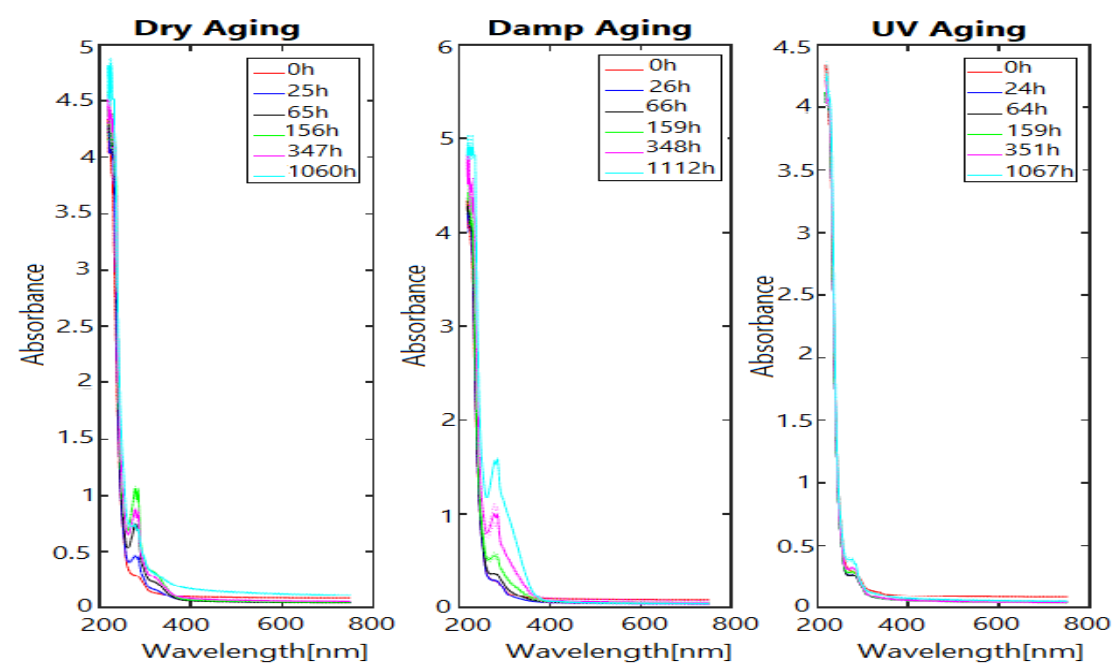

Figure 4. The general lowering of absorbance spectra of sample S4 caused by absence of Cyasorb under the effect of the different aging conditions of dry, damp, and UV heat.

Fluorescence measurement for aged samples

Measurement results of samples S3 and S4

fluorescence spectroscopy are shown in Fig.5 and 6 respectively. For UV and damp aging, increasing fluorescence intensity is proportional to aging time, but this is not completely true in the case of the dry heat. The reversion of fluorescence intensity of S3 specimen dry aging starts after aging time of $347 \mathrm{~h}$. While at $156 \mathrm{~h}$ for S4 it starts by delay duration of $191 \mathrm{~h}$ and delay rate of $55 \%$ at temperature $115^{\circ} \mathrm{C}$. Rising values indicate growth numbers of emitter species and decreasing refers to the transformation or degradation of the same fluorophores with $\pi$ bond orbital energy wavelength ca.280 $\mathrm{nm}$. Rapid oxidation produces fluorophores to some extent, later they become as incorporated groups as islands, reducing the fluorophores number (14). Carbonyl group is the main expectable source of the fluorescence intensity rise. The applied excitation wavelength $280 \mathrm{~nm}$ is in harmony with the requested wavelength of electron promotion energy of the neutral bond to $\pi^{*}$, anti-bond orbital (15).

Deterioration of Cyasorb results in evolution crosslinking in EVA as a reason of higher emission fluorescence intensity. A reasonable increasing gel in copolymer structure without discoloration is apparent of Cyasorb degradation. As consumption exceeds $70 \%$ of the total concentration a yellowing is yielded by carbon double bond $C=C$ creation (16).
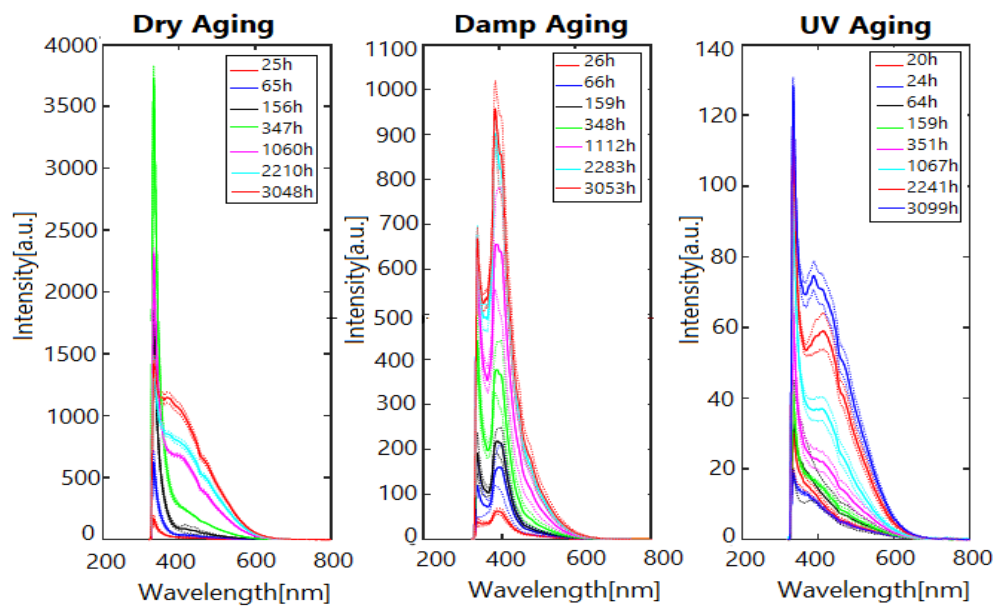

Figure 5. effect of the different accelerated aging types of dry, damp, and UV conditions on the fluorescence emission from the sample S3.

Degradation development in EVA gives additional products following the deacetylation process as an evidence refering to the formation of hydroxyl/hydroperoxide species, ketone groups, $\alpha, \beta$-unsaturated carbonyl groups, conjugated dienes, lactones and various substituted vinyl types (17). The regression of fluorescence intensity happens just for the short wavelengths (320-400 nm) of 
spectra, but not for the tails especially for longer than $(400 \mathrm{~nm})$.

At dry aging time of $3048 \mathrm{~h}$, the last spectrum of both samples S3 and S4 has approximately similar shapes and intensity values. Then the copolymer might be transformed to another new species and lower fluorescence intensity. The separated carbonyl group number is dropped in the least state progressively. Therefore, the lowest response of fluorescence intensity of excitation wavelength becomes at $280 \mathrm{~nm}$.

The behavior of the samples S3 and S4 for the damp aging shows a similarity in spectra, as both have double bands but with an important difference. The new band at a wavelength of 385 $\mathrm{nm}$ is not found in all other aging conditions, just as damp aging. This second band is higher than the appearing portion of the first band of the sample S3 spectrum and on the contrary, for sample S4 spectrum. The second band can be attributed to the influence of moisture. Then the appearing second band could be related to the moisture effect upon samples. Fluorescence intensity values refer to the penetration quantity of molecules of water vapor inside EVA samples which decreases the polymer service life (18). This strong effect links to water vapor hydrolysis reaction at $85{ }^{\circ} \mathrm{C}$ with EVA. As passage measure of water vapor or moisture through a substance is expressed by water vapor transmittance ratio (WVTR). The ratio value of EVA at $85{ }^{\circ} \mathrm{C}$ is ca. 100 g. $\mathrm{m}^{-2}$, temperature plays a very important role in this effect (18). Cyasorb has a property of hydrolysis, decomposed by reacting with water (19). The presented conditions raise the possibility of water vapor - additive reaction. The chemical reaction speed and acquired additive occupation volume accelerate water diffusion through $\mathrm{S} 3$ sample. The temperature of $85{ }^{\circ} \mathrm{C}$ alone has no effective impact (6), unless combined with moisture influence. To this limit, diffusion factor emerges as an important degradation influence; here we recall that the polymers have different values of WVTR (18). Therefore, the spectral intensity of S4 (UV absorber free) at damp aging shows higher fluorescence till the extent $159 \mathrm{~nm}$ then fluorescence intensity elucidates a rapid regression comportment.
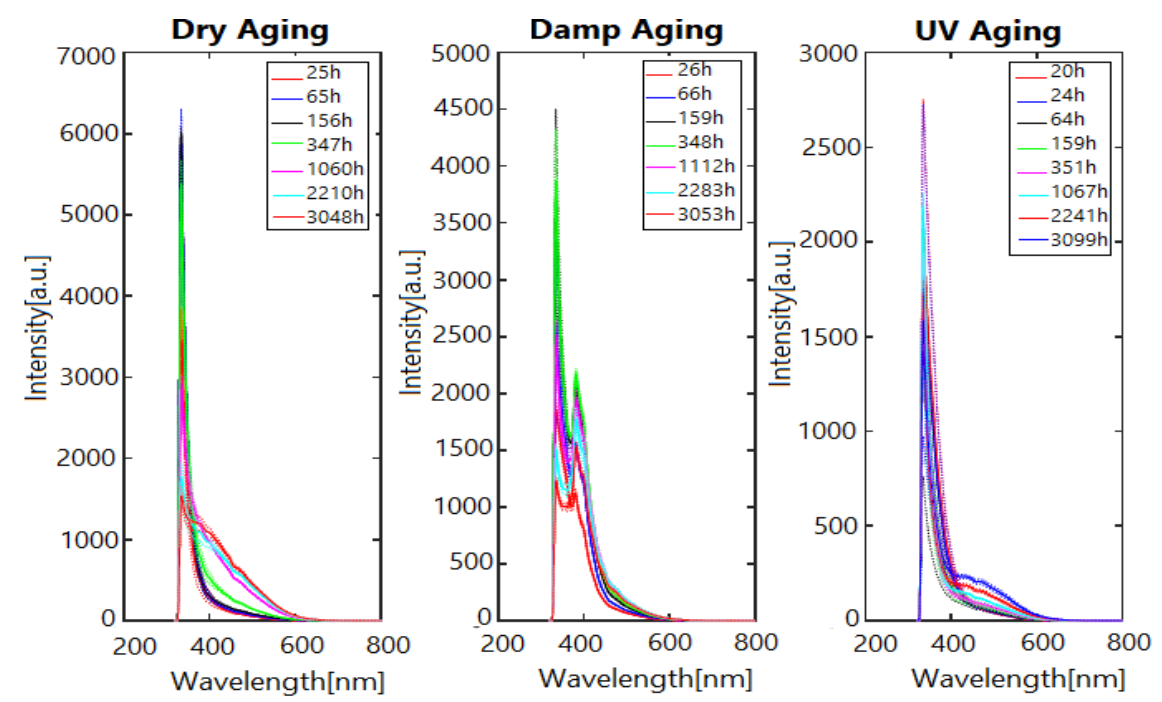

Figure 6. variation of fluorescence spectroscopy of sample S4 caused by the three different accelerated aging of dry, damp, and UV conditions.

which does not occur for sample S3, see Fig.5 and 6. The highest value of S4 at damp aging $159 \mathrm{~h}$ and intensity value 4500 au seem more affected than S3 sample status at dry aging of maxima $347 \mathrm{~h}$ and intensity value ca.3800 au, Fig.5. Then damp aging is more severe than dry heat in this case by the time progression rate of $45.8 \%$. The latter percentage is the same for S3 degradation delay by Cyasorb impact with respect to S4 at dry aging condition.

\section{Spectroscopy kinetics absorbance}

Kinetics curve in this work is a projection of points which represent the integrated area under intensity spectrum in Figs.3,4,5, and 6 for each a specific value of aging time.

The represented values are gathered and fitted into two groups with different marks of points for each sample. The used equations of fitting are; $y=r * \exp (-b x)$ and $y=r *(1-\exp (-b x))$ for samples S3 and S4 respectively. Where $r$ is the signal amplitude and $b$ is the rate constant of the reaction speed which shows the general reaction speed behavior of reactant concentration to yield the 
products. $x$ refers to the time independent variable. This curve is governed by increasing and decreasing of concentricity for the reactants and products. As known, absorbance refers the absorbed wavelengths or in other word non-transmitted wavelengths (20). There are two different actions in Fig.7, the general decline of absorbance or rising EVA transmittance for the sample S3 in Fig.7a on the contrary in the case of S4, Fig.7b.

At damp and UV aging conditions for S3, Fig.7a, absorbance decreasing almost is linear and has a comparable reaction speed (rate constants). The reaction of dry heat exponentially decreases with speed (about 29 double) higher than that of other conditions. Then dry heat at $115{ }^{\circ} \mathrm{C}$ is the most aggressive to vitiate Cyasorb than the other

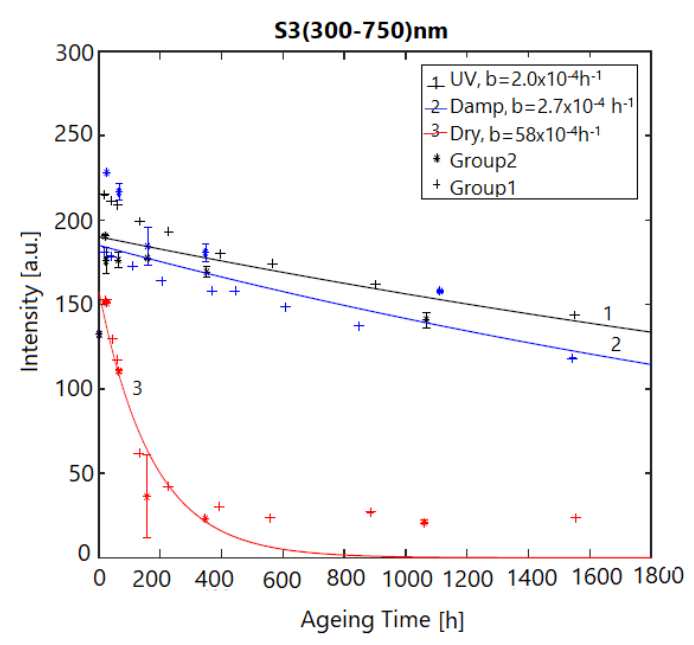

(a) two conditions (see Fig.3). Because of the high impact of additive, EVA degradation susceptibility by accelerating UV and damp aging conditions are slower than an effect of dry heat. If we imagine the degradation of UV absorber by UV and damp aging continues for a long interval, then perhaps absorbance would reach the steady state as that of dry condition.

Fig.7b shows the big effect of damp aging to decrease the transmittance or increase the absorbance possibly due to the overlapping absorbance bands by heat and moisture, Fig.3b (9). The initial part of the damp aging curve is not very steep as much as in the other curves of the dry and UV aging kinetics.

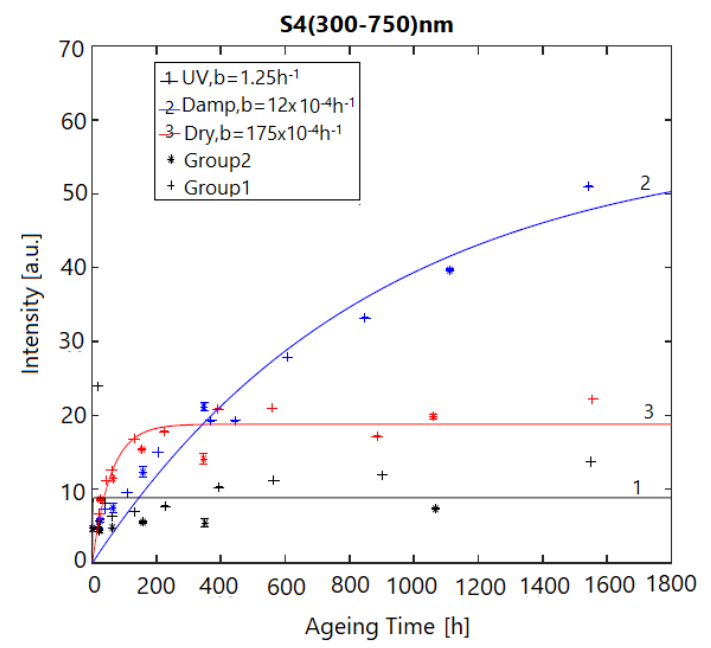

(b)

Figure 7. spectroscopy kinetics absorbance for three conditions of dry, damp, and UV aging of the samples (a) S3 (b) S4.

\section{Spectroscopy kinetics fluorescence}

The spectroscopy kinetics of absorbance and fluorescence both have the same representation way. Some fluorescence spectra overlap, especially that of dry heat, see Fig.5 and 6, within approximately the wavelength domain $320-400 \mathrm{~nm}$. At longer wavelengths, spectra are regular. As every reproducible spectral development by different aging times is accompanied by shape deformation refers to changes in the molar extinction coefficient. This coefficient relies on light wavelength, absorber's structure, orientation and environment (21). The structural change of material is very likely to happen for fluorescence wavelength less than ca. $400 \mathrm{~nm}$. The emission of longer wavelengths produces regular spectra without overlapping by aging time progression owing to fluorophore concentration increasing. Therefore, the kinetics of each of the two samples S3 and S4 is characterized in two Figs., according to the mentioned wavelengths fields, see Fig. 8. The source of the emitted fluorescence is fluorophore of double, triple bonds and/or aromatic ring of whatever chemical species (18). For sample S3 behavior, Fig.8a and b, is in accordance with the following reaction rate equation:

$r=-b[A]^{x}[B]^{y}$.

Where $\mathrm{b}$ is the rate constant, $\mathrm{A}$ and $\mathrm{B}$ are the concentration of species (in molar), $\mathrm{x}$ and $\mathrm{y}$ are the partial reaction orders (8).

The values of rate constant (b) are extracted from the fitting of the kinetic curves of sample $\mathrm{S} 3$, Fig.8a and $\mathrm{b}$ are shown in Table 2. The redshift of wavelengths, especially in damp aging is resulted by water vapor diffusion in the polymer and degradation of additive in sample S3. The most probable reason belongs to associated energy density decline with increasing free volume throughout phase transformation (22). It is worthy, noting that the percentage proportion change of rate constants indicates an extent of the conversion reaction speed of the material structure. We can see 
the highest percentage is that of the damp aging of $66.7 \%$. The damp condition works on facilitating the permeation of the molecules of water inside the sample of S3. The existence of water molecules at the surface by adsorption in addition to probable diffusion inside the material offers a good chance to touch the particles of Cyasorb. The latter has the ability to interact with water by the solubility of $0.00073 \mathrm{mg} / \mathrm{L}$ at $20^{\circ} \mathrm{C}$.

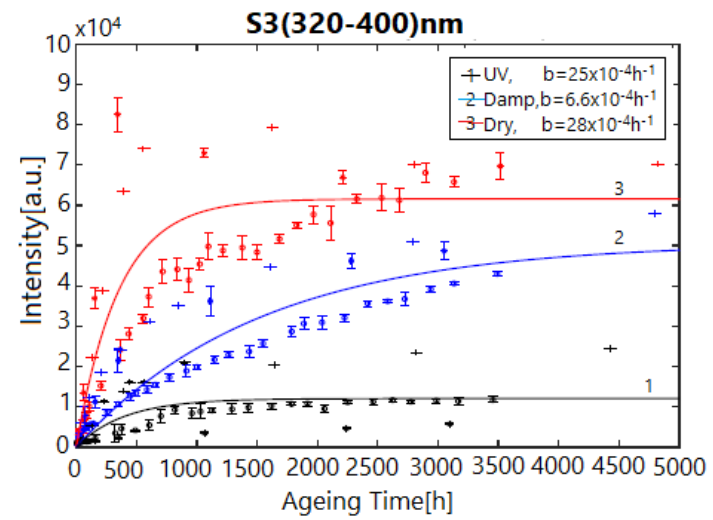

(a)

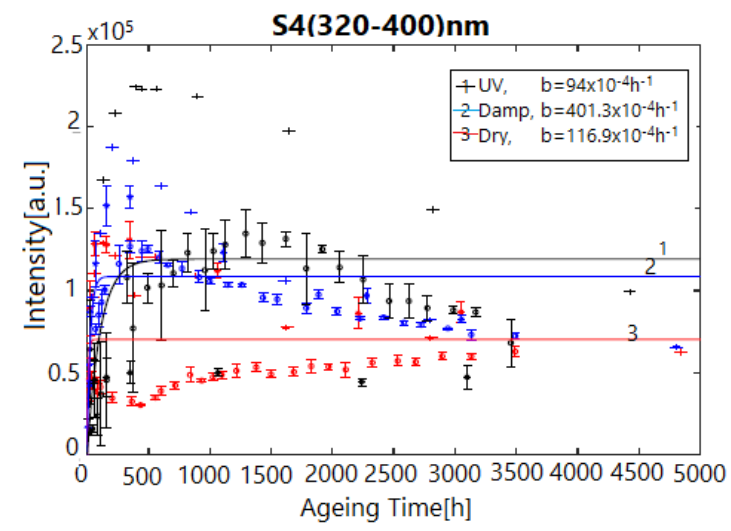

(c)
Boost of this value is very expected because of vapor and high temperature $85{ }^{\circ} \mathrm{C}$. It is known that the melting temperature of Cyasorb is $47-50{ }^{\circ} \mathrm{C}$ (23).

It may be helpful to recall that the percentage rate of oxygen in the air is $21 \%$, whereas the dissolved oxygen in water is a tiny fraction of 1 percent $(24,25)$.

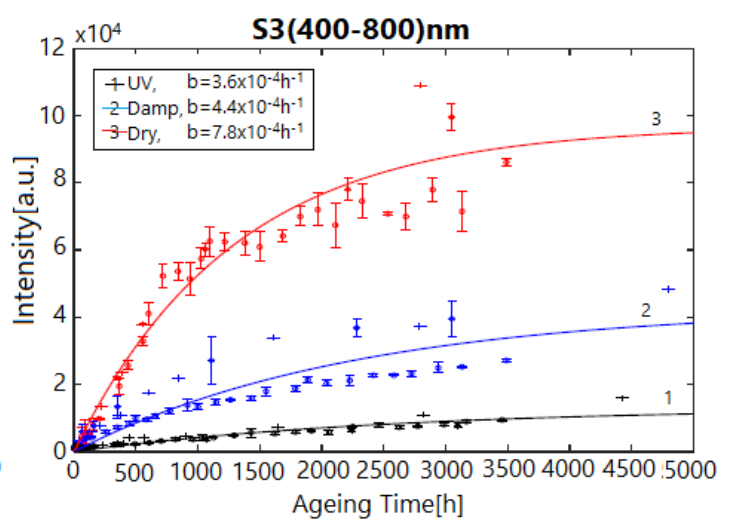

(b)

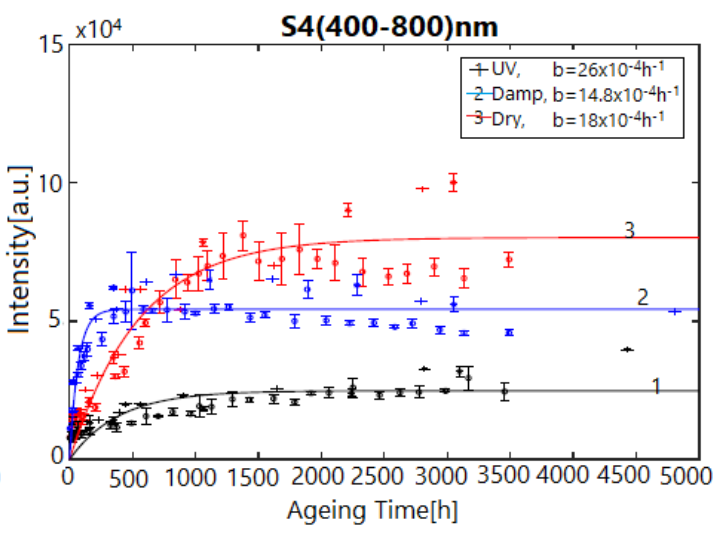

(d)

Figure 8. variation of spectroscopy kinetics of fluorescence according to the three aging conditions dry, damp, and UV heat for (a) S3 (320-400nm), (b) S3 (400-800 nm), (c) S4 (320-400 nm), and (d) S4 (400$800 \mathrm{~nm})$.

Table 2. Rate constant values of S3 of short and long wavelengths for different aging conditions. For all conditions there is always decreasing in rate constant value at long wavelengths in comparison with those of short wavelengths.

\begin{tabular}{cccc}
\hline Aging Condition & Dry & Damp & UV \\
\hline $\begin{array}{c}\text { Rate Const. } \times 10^{-4} \mathrm{~h}^{-1} \\
(320-400 \mathrm{~nm})\end{array}$ & 28 & 6.6 & 25 \\
$\begin{array}{c}\text { Rate Const. } \times 10^{-4} \mathrm{~h}^{-1} \\
\quad(400-800 \mathrm{~nm})\end{array}$ & 7.8 & 4.4 & 3.6 \\
\begin{tabular}{c} 
Decreasing Rate $\%$ \\
\hline
\end{tabular} & 27.9 & 66.7 & 14.4 \\
\hline
\end{tabular}

In the latter case of UV aging, the additive of UV absorbers play an important role in absorbing UV radiation and dissipate it as non-irradiated energy at temperature $65^{\circ} \mathrm{C}$. Temperature is not too high to cause a distinct degradation, shape variation, and chemical structure change for sample S3.

For sample S4, Fig.8c and d, the general behavior is different from the two pictures, Fig. $8 \mathrm{a}$ and $b$ (Table 3 ). These two cases could be originated from unlike chemical species, according to the fitted lines of kinetics curves for the two different wavelength domains. 
Table 3. Rate constant values of S4 of short and long wavelengths for different aging conditions. For all conditions there is always decreasing in rate constant value at long wavelengths in comparison with those of short wavelengths.

\begin{tabular}{cccc}
\hline Aging Condition & Dry & Damp & UV \\
\hline Rate Const. $\times 10^{-4} \mathrm{~h}^{-1}$ & 1169 & 401 & 94 \\
$\quad(320-400 \mathrm{~nm})$ \\
$\begin{array}{c}\text { Rate Const. } \times 10^{-4} \mathrm{~h}^{-1} \\
(400-800 \mathrm{~nm})\end{array}$ & 18 & 148 & 26 \\
Decreasing Rate \% & 1.5 & 36.9 & 27.7 \\
\hline
\end{tabular}

From the values of rate constants, at short wavelengths the reaction of dry heat is the fastest, then damp and at last UV aging. For long wavelengths, the values in general decrease, but not in uniform as the reaction of damp aging is the fastest then of UV and at the end the dry reaction. The percentage rates of the decreasing are $1.5 \%$, $36.9 \%$, and $27.7 \%$ of the dry, damp, and UV aging respectively. They refer to the changes in the chemical structure of EVA material, which leads to change the molar extinction coefficient and spectra overlapping but just for the short wavelength domain. The highest percentage is $36.9 \%$ by damp aging for the same reasons which are mentioned for the sample S3. Therefore, dissolving this material is unexpected and this is why the percentage is lower than that of sample S3 by $55.3 \%$. Also, it can be noted that the high percentage of the chemical structure change of sample S4 is affected by UV aging. In comparison with the case of sample S3 the increasing ratio is $12.3 \%$ because of missing UV absorber. The predictable change in the material structure of sample $\mathrm{S} 4$ by the dry heat of $115^{\circ} \mathrm{C}$ is the least among the other aging conditions. The reduction rate, as we stated, is $1.5 \%$. The material of sample S4 is more homogeneous than that of sample S3. Consequently, sample S3 suffers from higher chemical structure change by a ratio of $72.2 \%$ than sample S4 owing to the existence of Cyasorb in sample S3.

\section{Conclusion:}

The UV absorber presence in EVA in comparison with other Cyasorb-free EVA samples causes higher absorbance and lower fluorescent intensity emission. EVA specimens have been exposed to accelerated aging (dry, damp, and UV heat). The conditions qualitatively simulate natural influences. Cyasorb additive progressively suffers from severe degradation by the aging time of dry heat at $115{ }^{\circ} \mathrm{C}$. But in two other surroundings of damp aging $\left(85 \%\right.$ moisture and $\left.85{ }^{\circ} \mathrm{C}\right)$, and UV irradiation at $65{ }^{\circ} \mathrm{C}$, Cyasorb appears in better stability.
Fluorescence spectra of EVA samples with and without UV absorbers show two characteristic regions depending on the wavelength values. The first region 320-400 $\mathrm{nm}$ of short wavelengths has high spectra overlapping in accordance with the several aging times. The second long wavelengths field 400-750 $\mathrm{nm}$ have no spectra superposition by aging time. Absorbance spectroscopy kinetics show exponentially decreasing in absorbance of samples with Cyasorb. Approximately, a slower linear decreasing in absorbance is observable for damp and UV heat aging conditions. While Cyasorb-free samples absorbance kinetics refer to exponentially increase in elevation absorbance or in other words, steep decreasing in the transmittance.

From spectroscopy kinetics fluorescent of EVA, samples contain Cyasorb, reaction rate being in general at the highest speed by dry aging $115^{\circ} \mathrm{C}$ and at the lowest speed by UV aging. But for Cyasorb-free samples reaction rate speed of damp condition is the fastest and the slowest speed of dry aging, for the same wavelengths of short 320-400 $\mathrm{nm}$ and long 400-750 $\mathrm{nm}$ domain.

The existence of Cyasorb in EVA samples causes the highest chemical structure change by damp aging and the lowest by the UV aging, while in case of Cyasorb absence in EVA samples keep the highest chemical structure change by damp aging and the lowest change by dry aging. In general, the chemical structure deformation in the samples of group one (includes UV absorber) is greater than that of group two (Cyasorb-free). This assessment of chemical structure deformation ratio based on the ratio of rate constant value for long wavelengths to that of short wavelengths.

\section{Acknowledgements:}

This work is supported by the Iraqi ministry of HESR. Special thanks to Prof. Beate Röder, Dr. Ronald Steffen and the group of Photobiophysics (PBP AG), Humboldt-Universität zu Berlin for their help.

\section{Authors' declaration:}

- Conflicts of Interest: None.

- We hereby confirm that all the Figures and Tables in the manuscript are mine ours. Besides, the Figures and images, which are not mine ours, have been given the permission for republication attached with the manuscript.

- Ethical Clearance: The project was approved by the local ethical committee in University of Babylon. 


\section{References:}

1. Hülsmann P, Wallner GM. Permeation of water vapor through polyethylene terephthalate (PET) films for back-sheets of photovoltaic modules. Polym Test. 2017;58:153-8.

2. Bhuwanesh S,Umang D, Ashish S, Aparna S. Effect of vinyl acetate content on the photovoltaicencapsulation performance of ethylene vinyl acetate under accelerated ultra-violet aging, 2019 Wiley Periodicals. Inc. J. Appl. Polym. Sci. 2019, 136, 48268.

3. Wang X, Barnett A. Article: The Evolving Value of Photovoltaic Module Efficiency. Appl. Sci. 2019; 9(6): 1227.

4. Jiang S, Wang K, Zhang H, Ding Y, Yu Q. Encapsulation of PV modules using ethylene vinyl acetate copolymer as the encapsulant. Macromol React Eng. 2015;9:522-9.

5. Badiee A, Wildman R, Ashcroft I. Effect of UV Aging on Degradation of Ethylenevinyl acetate (EVA) as Encapsulant in Photovoltaic (PV) Modules. Reliability of Photovoltaic Cells, Modules, Components, and Systems VII. Proceedings of SPIE. 2014; 9179: 1-7.

6. Schneller EJ, Brookera RP, Shiradkarb NS, Rodgersb MP, Dhereb NG, Davisa KO, et al. Manufacturing metrology for c-Si module reliability and durability Part III:module manufacturing. Renew. Sust. Energ. Rev. 2016;59:992-1016.

7. Badiee A, Ashcroft IA, Wildman RD. The thermomechanical degradation of ethylene vinyl acetate used as a solar panel adhesive and encapsulant. Int. J Adhes. 2016;68:212-8.

8. Ottersböck B, Oreski G, Pinter G. Comparison of different microclimate effects on the aging behavior of encapsulation materials used in photovoltaic modules. Polym Degrad Stab. 2017;138:182-91.

9. Steffen R, Akraa MA, Röder B. Kinetics of degradation-induced photoluminescence in ethylenevinyl-acetate as used in photovoltaic modules, SOLMAT, 2019 ; https://doi.org/10.1016/j.solmat.2019.110294.

10. Hasan O, Arif AFM. Performance and life prediction model for photovoltaic modules: effect of encapsulant constitutive behavior. SOLMAT. 2014;122:75-87.

11. Sultan B $\AA$, Sörvik E.Thermal degradation of EVA (ethylene-vinyl acetate copolymer) and EBA (ethylene-butyl acrylate copolymer) - a comparison. II. Changes in Unsaturation and Side Group Structure. J. Appl. Polym. Sci., 1991; 1748:43-59.

12. Herman M. Encyclopedia of polymer science and technology, Concise third edition, A John Wiley \& Sons, Inc., Publication, 2007.

13. Reid CG, Bokria JG, Woods JT. Accelerated UVAging of EVA-based PV Encapsulants and
Correlation with Outdoor Exposure of PV Modules. Specialized Technology Resources, Inc., (STR Solar). Proceedings of the 2nd Atlas/NIST workshop on PV materials durability. Gaithersburg, MD, USA; 2013 [cited 2017 Fev 07].

14. Rodriguez-Vazquez M, Liauw M, Allen S, Edge M, Fontan E. Degradation and Stabilisation of poly (ethylene-stat-vinyl acetate): 1 - Spectroscopic and Rheological Examination of Thermal and ThermosOxidative Degradation Mechanisms. Polym Degrad Stab. 2006; 91: 154-164.

15. Galica J. Internal Memorandum, Springborn Laboratories, Covering Meeting at SERI, 1990.

16. Upadhyay SK. Hand Book, Chemical Kinetics and Reaction Dynemics, Springer\&Anamaya Publishers, 2006.

17. Steffen R, Wallner G, Rekstad J, Röder B. General characteristics of photoluminescence from dry heat aged polymeric materials, Polym Degrad Stab, 2016; 134: 49-59.

18. Zhu J, Montiel-Chicharro D, Betts T, Gottschalg R. Correlation of Degree of EVA Crosslinking with Formation and Discharge of Acetic Acid in PV Modules, A Conference Paper presented at the $33^{\text {rd }}$ European Photovoltaic Solar Energy Conference and Exhibition. 2017, Amsterdam, 25-29th.: 1795 - 1798.

19. Giuseppina M, Giulia Z,Daniel R, Jordi H, Claudio $\mathrm{R}$, Loredana L. Thermal Control of Intermolecular Interactions and Tuning of Fluorescent-State Energies, ACS Publications. J. Phys. Chem. 2019; C20191238: 4632-4637.

20. Gagliardi M., Lenarda P., Paggi M. A reactiondiffusion formulation to simulate EVA polymer degradation in environmental and accelerated aging conditions. SOLMAT. 2017; 164: 93-106.

21. Omastova M, Cikova E, Micusik M. Electrospinning of Ethylene Vinyl Acetate/Carbon Nanotube Nanocomposite Fibers. Polymers J. 2019; 11(3), 550.

22. Fraunhofer Institute for Solar Energy Systems. ISE with support of PSE Conferences \& Consulting GmbH. Photovoltaics Report, Fraunhofer ISE, Freiburg, Germany, 2019.

23. Mutsumi T, Yogetsu B. Difference in Surface Roughness of Ethylene-Vinyl-Acetate Sheet before and after Application of Finishing Liquid: Part 2 Changes over Time in Surface Roughness. JMSA.2019; 10: 451-460.

24. Bernadette C, Timothy J. Permeation of a Range of Species through Polymer Layers under Varying Conditions of Temperature and Pressure: In Situ Measurement Methods. Polymers J. 2019; 11: 1056.

25. Stockert C, Castro B. Fluorescence Microscopy in Life Science, Bentham Science Publishers - Sharjah, UAE, 2017. 


\section{التوصيف الطيفي لتحلل اثلين فنيل الخلات بواسطة انواع مختلفة من التعتيق المعجل \\ محمد جواد هادي كاظم

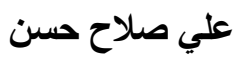 \\ محمد عبد الحمزة أكرع}

قسم هندسة البوليمير ات و المنتجات البتروكيمياوية، كلية هندسة المو اد، جامعة بابل، بابل، العراق.

الخلاصة:

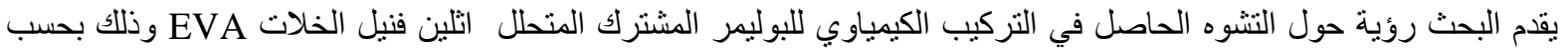

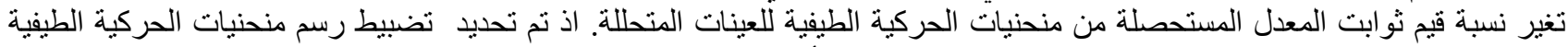

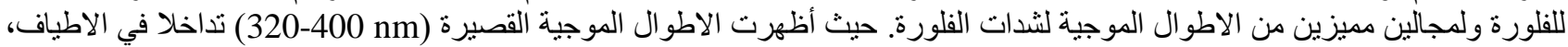

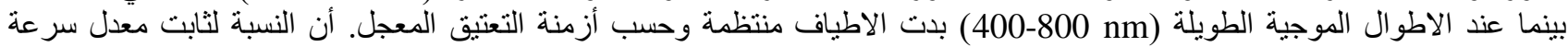

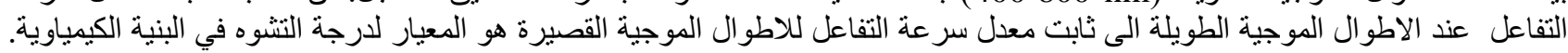

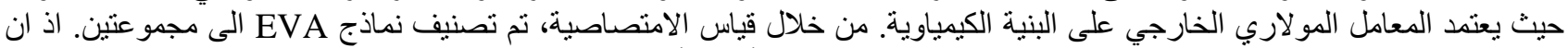

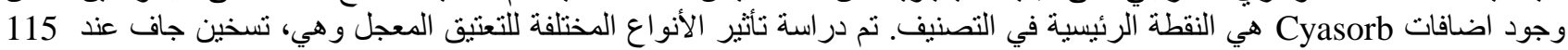

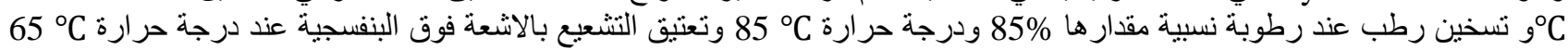

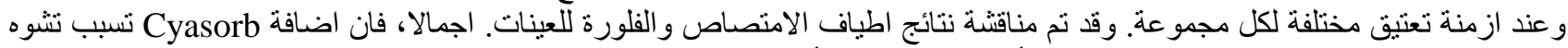

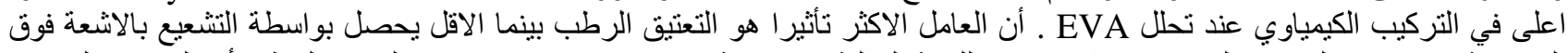

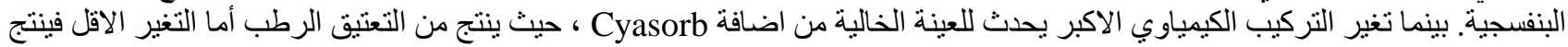

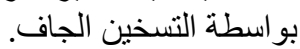

الكلمات المفتاحية: اثلين فنيل الخلات، التعتيق المعجل، التحلل الحراري للبوليمر، تلألؤ الحالة الصلبة، توصيف التعتيق. 